\title{
Retraction Note to: Effect of alendronate on bone mineral density and bone turnovermarkers in post-gastrectomy osteoporotic patients
}

\author{
Jun Iwamoto ${ }^{1} \cdot$ Mitsuyoshi Uzawa $^{2} \cdot$ Yoshihiro Sato $^{3} \cdot$ Tsuyoshi Takeda $^{1} \cdot$ Hideo Matsumoto ${ }^{1}$
}

Published online: 6 February 2021

(c) The Japanese Society Bone and Mineral Research 2021

\section{Retraction to: J Bone Miner Metab (2010) 28:202-208 https://doi.org/10.1007/s00774-009-0116-0}

The Editors-in-Chief have retracted this article [1] because approval from the Keiyu Orthopedic Hospital ethics committee was not obtained before the study commenced.

Jun Iwamoto and Hideo Matsumoto have not responded to correspondence from the Editors-in-Chief or the Publisher about this retraction. The Editors-in-Chief have not been able to obtain current email addresses for Tsuyoshi Takeda and Mitsuyoshi Uzawa. Yoshihiro Sato is deceased.

\section{Reference}

1. Iwamoto J, Uzawa M, Sato Y, Takeda T, Matsumoto H (2010) Effect of alendronate on bone mineral density and bone turnover markers in post-gastrectomy osteoporotic patients. J Bone Miner Metab 28:202-208

Publisher's Note Springer Nature remains neutral with regard to jurisdictional claims in published maps and institutional affiliations.

The original article can be found online at https://doi.org/10.1007/ s00774-009-0116-0.

Jun Iwamoto

jiwamoto@sc.itc.keio.ac.jp

1 Institute for Integrated Sports Medicine, Keio University

School of Medicine, 35 Shinanomachi, Shinjuku-ku,

Tokyo 160-8582, Japan

2 Department of Orthopaedic Surgery, Keiyu Orthopaedic

Hospital, Gunma, Japan

3 Department of Neurology, Mitate Hospital, Fukuoka, Japan 